\title{
Preliminary Study on the Mechanical Behavior of Friction Spot Welds
}

\author{
(Estudo Preliminar do Comportamento Mecânico de Soldas a Ponto por Friçcão)
}

\author{
José Antônio Esmerio Mazzaferro ${ }^{1,2}$, Tonilson de Souza Rosendo ${ }^{1,2}$, Cíntia Cristiane Petry Mazzaferro ${ }^{1,2}$, Fabiano Dornelles Ramos ${ }^{2,3}$, \\ Marco Antônio Durlo Tier ${ }^{2,3}$, Telmo Roberto Strohaecker ${ }^{1}$, Jorge Fernandes dos Santos ${ }^{2}$. \\ ${ }^{1}$ Universidade Federal do Rio Grande do Sul/PROMEC-DEMEC, Porto Alegre, Rio Grande do Sul, Brazil \\ ${ }^{2}$ GKSS Research Centre/Institute of Materials Research-Materials Mechanics Solid State Joining Processes (WMP), Geesthacht, \\ Germany \\ ${ }^{3}$ Universidade das Missões/Departamento de Engenharia e Ciências de Computação, Santo Ângelo, Brazil \\ mazza@ufrgs.br
}

\begin{abstract}
The Friction Spot Welding - FSpW is a solid-state process that allows joining two or more metal sheets in lap configuration with no residual keyhole as occurs in the Friction Stir Welding - FSW process. The present work reports part of the efforts made at GKSS Research Centre to better understand the complex phenomena that take place during FSpW of aluminum alloys and establish the mechanical response of the resulting joints. Over the recent years the research on modeling friction based welding processes has increased considerably. Most of the works related to this subject deal with the process mechanics. On the other hand, some investigations have shown how the process variables affect the mechanical properties of the joints, but it is very difficult to find quantitative results that can be readily used for mechanical design purposes. The aim of this work is to develop an analysis procedure based on the process characteristics that allows evaluating how the resulting geometry and microstructure affect the joint mechanical behavior. For this, the results of the mechanical tests obtained on AA2024-T3 aluminum alloy were used to calibrate and validate a numerical model that was used to predict the joint failure mode. The model reproduced the specimen geometry and load conditions adopted in the lap-shear and cross-tensile tests. The joint was considered as formed by three main regions (SZ - stir zone, TMAZ - thermo mechanically affected zone and HAZ - heat affected zone) whose properties and dimensions were based in microhardness evaluation and macrographic analysis of welded specimens. It was observed a good agreement between the simulation results and experimental data. The numerical modeling of the joints allows the prediction of the joint mechanical properties, as well as to understand how a change in geometry and property of each region affects the final mechanical behavior. Based in the obtained results, the analysis procedure can be easily extended to the related friction based spot processes as Friction Stir Spot Welding - FSSW.
\end{abstract}

Key-words: Friction Spot Welding, FSpW, failure mode

Resumo: O processo de Soldagem a Ponto por Fricção (FSpW - Friction Spot Welding) caracteriza-se por possibilitar a união no estado sólido de duas ou mais chapas de material sobrepostas sem deixar o furo residual característico do processo FSW. O presente trabalho apresenta os primeiros resultados de estudos visando determinar a resistência mecânica de juntas em ligas de alumínio soldadas por FSpW. Recentemente diversos estudos sobre o modelamento numérico de soldas realizadas por processos de soldagem baseados em fricção têm sido realizados, entretanto a maioria destes estudos está relacionada à física do processo. Alguns trabalhos estabelecem a relação entre as variáveis de processo e as propriedades mecânicas da junta resultante, mas é muito difícil encontrar na literatura resultados quantitativos que possam ser usados diretamente para projeto destas uniões. O presente trabalho objetiva desenvolver um processo de análise baseado nas características do processo que permita avaliar como a geometria e microestrutura das regiões da solda afeta o comportamento mecânico das juntas resultantes. Com este objetivo, os resultados de ensaios mecânicos realizados em juntas de alumínio AA2024-T3 foram usados para validar e calibrar um modelo numérico desenvolvido para prever o modo de falha da união. O modelo numérico reproduz as dimensões e carregamento utilizados nos ensaios de cisalhamento e traçao. As dimensões e propriedades das regiões principais da junta (ZM - zona de mistura, ZTMA - zona termo-mecânicamente afetada, ZAC - zona afetada pelo calor e MB - metal base) foram definidas com base na medição da dureza e análises macrográficas de corpos de prova soldados com diferentes parâmetros. Pode-se comprovar uma ótima correlação entre os resultados obtidos nas simulações e os dados experimentais. O modelamento numérico das juntas pernite a previsão das propriedades mecânicas da junta e auxilia na compreensão da influência da geometria e propriedades de cada região sobre o seu desempenho em serviço. Baseado nos resultados obtidos, o procedimento de análise pode ser facilmente adaptado para o processo de Soldagem a Ponto por Fricção e Mistura Mecânica (FSSW - Friction Stir Spot Welding).

(Recebido em 05/11/2008; Texto Final em 14/08/2009). 
Palavras Chave: Soldagem por fricção a ponto, modo de falha

\section{Introduction}

The research associated to friction based process has considerably increased in the last years. This fact can be explained by the various advantages of these processes when compared to the conventional fusion welding process. The advantages become more evident in situations where the conventional process simply cannot be used, as in case of difficult weldability or when joining dissimilar materials.

The focus of the work was concentrated in the development of a computer model to simulate the welding joint behavior under typical loading conditions.

Currently, the analysis had been concentrated on the Friction Spot Welding (FSpW), a spot welding process invented and patented by GKSS. This process can represent an alternative to conventional spot welding processes like Resistance Spot Welding (RSW) and Riveting if could be demonstrated that the mechanical behavior of the resulting joints is similar. In this way, the numerical simulation can be an attractive and efficient instrument to decrease the number of actual welding tests, shortening the technology development time in this area. Even, the possibility of test virtually the effect of different weld conditions/parameters over the resulting mechanical behavior and predict the failure mode under typical load conditions, can make simulation an useful instrument in estimation of potential service performance of mechanical elements containing FSpW joints.

Although some experience from previous studies has been obtained in dealing with the related process FSW, the Friction based Spot Welding Processes present their particular characteristics and joint mechanical behavior.

Since the FSW process was primarily developed and known as a potentially new important welding joining method, numerous studies have been conducted to allow a better understanding of its fundamentals. The first efforts to model analytically and numerically the FSW process had been conducted by Bendzsak et al in 1997 [11]. Others, such as Chao and Qi in 1999 [2] Colegrove in 2000 [3], Ulysse in 2002 [5], Xu et al [4] and Arbegast [6] in 2003, and Schmidt et all in 2004 [7] can be cited as significant contributors to the best understanding of the process physics, or proposed new methods to solve the highly non linear problem. These efforts are extended to FSSW and FSpW $[8,9,10]$ and the modeling methodologies are thought to become stronger instruments for future tool design, process optimization and control of these process.

Specifically in the friction based welding processes, these tools have been used to predict temperature, stress fields and material flow around the tool. The numerical and analytical models available in the literature present different approaches, assumptions and levels of complexity. In the present work the objective is not to simulate the FSpW process itself but produce a model that allows determining the resulting joint mechanical response.

\section{Model Development}

The numerical model was developed considering the specificities of the Friction Spot Welding process, the equipment used to produce the bonding region and the mechanical tests available for model validation.

\subsection{FSpW characteristics}

To correctly model the contact region between the welded plates, some characteristics of the welding equipment can be taken in consideration.

As seen in Figure 1 the welding machine consists basically of a main head, where tools of different geometries can be adjusted. The rotating tool, which can be also seen in the right hand side of the figure, exhibits no traverse movement, what means the joint geometry is symmetric in both longitudinal and transversal directions. In this way, the stir zone shape will depend only of tool geometry and the variant of the process chosen.

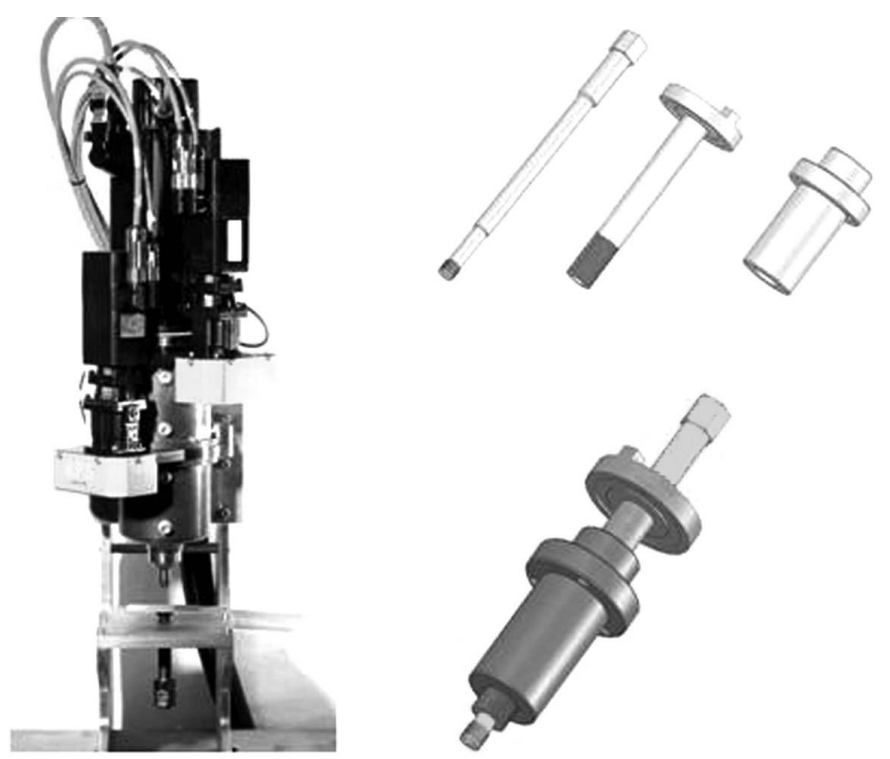

Figure 1. Prototype machine for FSpW and welding tool [12].

The FSpW tool is formed by an external clamping ring, a shoulder, and an internal pin. The model used in simulation was developed considering the dimensions of the tool used to produce the FSpW joints: the pin and shoulder diameters are respectively $5.2 \mathrm{~mm}$ and $9.0 \mathrm{~mm}$ [12].

Regarding the process variant, there are basically two ways the tool can penetrate in the plates, called the pin plunge and the shoulder plunge variants of the process.

It is important to know these two different possible ways to obtain a welded joint by FSpW to understand why the final aspect of the resulting welding regions is important and how it was taken in consideration for modeling purposes.

A sequence of relative movement between tool's parts during welding is shown schematically in Figure 2, to the two process variants. 

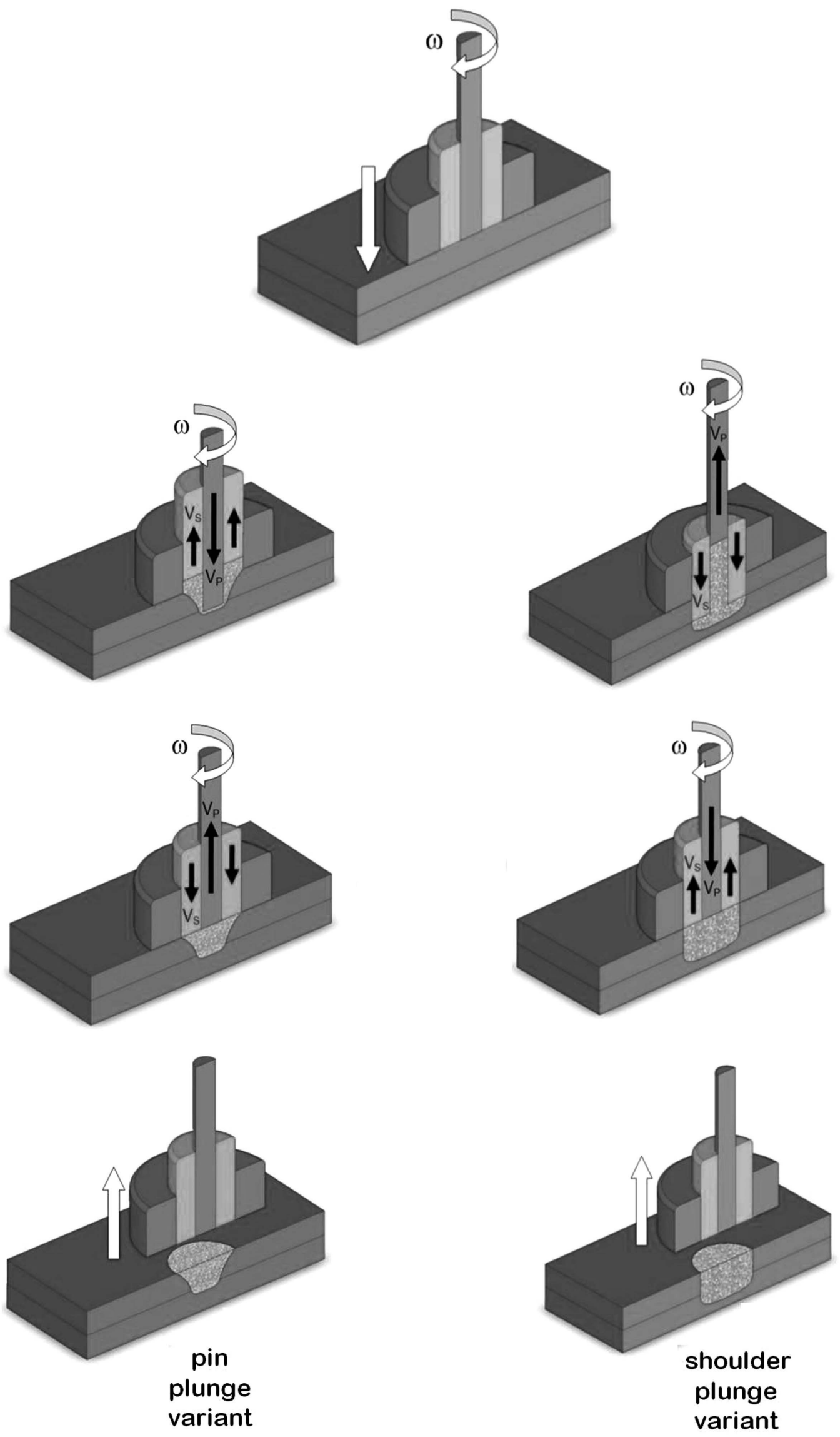

Figure 2. Schematic illustration of the FSpW process variants [13]. 
Once the contact is established, the sequence of steps shown on the left and right hand sides describes the pin plunge and shoulder plunge variants respectively.

As can be seen, in the first step of the pin plunge variant the shoulder retracts while the pin penetrates in the plates squeezing the plasticized base metal to fill up the cavity formed by the shoulder movement. In the shoulder plunge variant the relative movement between pin and shoulder occurs in opposite ways.

In the second stage pin and shoulder return to their initial position, corresponding to the top of the upper plate before the start of plunge step.

Finally, the tool retracts with no relative movement between its parts. The cross section of the resulting weld spots will be determined by this sequence of events. There are specific characteristics associated to each one of these variants, but what defines the joint strength is the shape of the resulting spot weld. All the experimental results presented in this work were obtained using the shoulder plunge variant, which produces a greater effective plates' contact area after welding.

Figure 3 presents some macrographic images of AA2024-T3 $\mathrm{FSpW}$ joints to different plunge depths and rotational speeds.

We can observe that, regarding the variation of the welding parameters, the stir zone width did not show evidence of change. Hence, the model geometry definition was based on tool dimensions and plates configuration actually used in mechanical tests.

Analyzing the macrographs, it is possible to observe the formation of regions with diverse grain sizes and orientations. These regions are designed Stir Zone-SZ, Thermo-Mechanically Affected Zone - TMAZ, Heat Affected Zone - HAZ and Base Metal - BM. A detailed description of their characteristics can be found in [13].

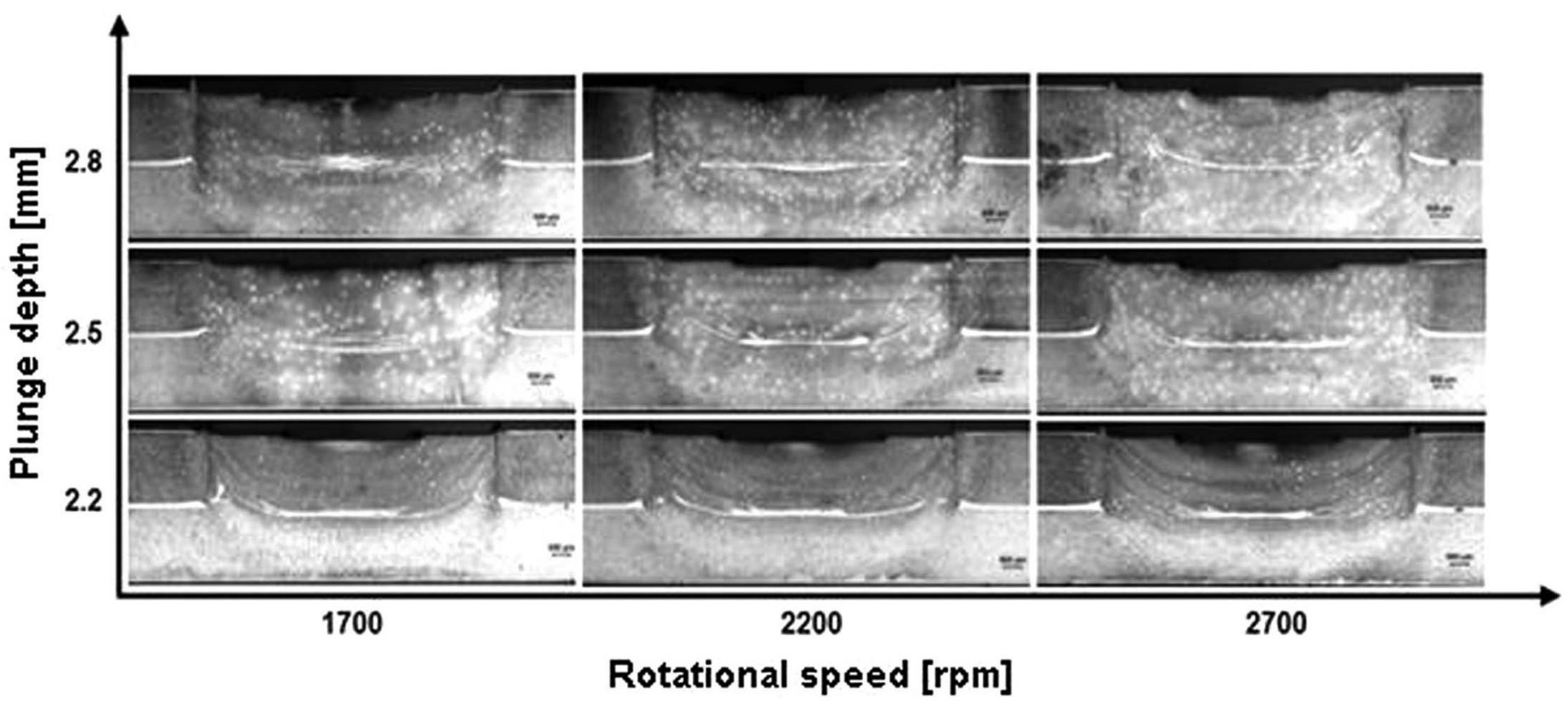

Figure 3. Macrographic images of different shoulder plunge FSpW joints of AA2024-T3 [12, 14].

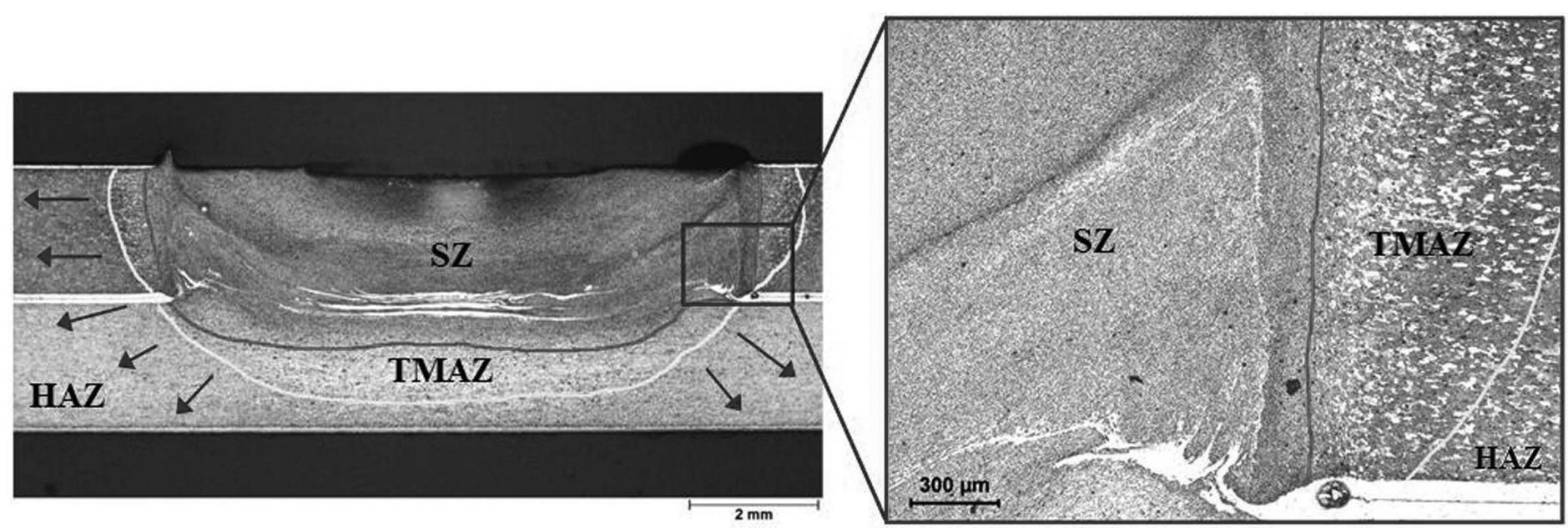

Figure 4. FSpW typical joint regions - SZ, TMAZ and HAZ [17]. 
In the macrographs is possible to easily identify the approximate boundary between SZ, TMAZ and BM, as seen in Figure 4. It is possible to verify that, depending on process parameters, the clad layer can be more or less dispersed in SZ. This was not considered in the numerical model. In the detail of Fig. 4 it is possible to see that there is a great difference in grain size between SZ and TMAZ, while grains of TMAZ and HAZ are similar.

Based in this general aspect of a typical joint produced by the tool used to perform the actual welds, the model joint geometry was defined as shown in the sketch of Figure 5.

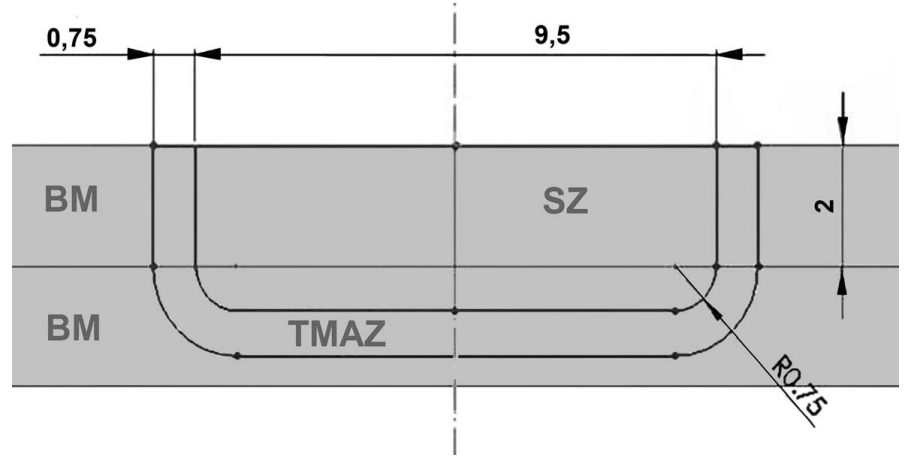

Figure 5. Geometry of the different welding zones definition for modeling purposes.
The sketch shows the interface between the two welded plates in lap configuration, as well as the different joint regions. The dashed blue line represents the centre of the weld, where the SZ can be seen exactly where the tool penetrates squeezing and plasticizing the base metal. Around the periphery of SZ is located the TMAZ, where a constant width of $0.75 \mathrm{~mm}$ was assumed, and beyond its external boundary, the BM that did not has experienced any microstructure change. The dimensions assumed for the regions were defined considering the simplicity to model using simple features like lines and curves, and that the critical points should coincide with plate boundaries to avoid errors in contact between the just created surfaces and mesh geometry. The values are function of tool geometry and processing parameters, not changing appreciably to the range of parameters studied. It is worth noting that no HAZ was considered in the model, what can be explained by the similar mechanical properties of these adjacent regions.

\subsection{Material Properties}

The base material used in the simulations was the Alclad AA2024-T3 $2 \mathrm{~mm}$ thick plate. This choice was based on its massive use in aircraft industry and the large number of experimental data available from previous works $[12,14,15,16$, 17]. The chemical composition of the alloy is shown in Table 1. The main mechanical properties of the alloy in $\mathrm{T} 3$ condition are: yield strength $\mathrm{e}=310 \mathrm{MPa}$, ultimate tensile strength $\mathrm{r}=448$ $\mathrm{MPa}$, elongation $=20 \%$.

Table 1. Chemical composition of the AA2024.

\begin{tabular}{|c|c|c|c|c|c|c|c|c|}
\hline Grade & $\mathbf{S i}$ & $\mathbf{F e}$ & $\mathbf{C u}$ & $\mathbf{M n}$ & $\mathbf{M g}$ & $\mathbf{Z n}$ & $\mathbf{T i}$ & $\mathbf{A l}$ \\
\hline $\mathbf{2 0 2 4}$ & 0.19 & 0.23 & 3.94 & 0.55 & 1.24 & 0.22 & 0.02 & bal. \\
\hline
\end{tabular}

Once the BM was chosen, the properties of the other weld regions should be defined. Since no mechanical test data on the properties of each region were available, the hardness profiles of an actual welded specimen were used to estimate these properties.

The graph shown in Figure 6 presents the hardness profile along the cross section of the joint at three different distances from the upper plate top surface. The vertical dashed lines define the approximate position of SZ and TMAZ boundaries.

Analyzing the hardness profile it is observed that there was no significant change in hardness between the different regions. We can see a slightly hardness decrease in the boundary region between TMAZ and BM.

Based on the hardness profile, three different property settings were assumed (Figure 7).

The middle line shows the engineering stress-strain curve corresponding to the base metal properties. It was assumed that in the SZ region the mechanical resistance is $5 \%$ greater than that in the base metal, as indicates the upper line. On the other hand, in the TMAZ, a decrease of 5\% from base metal resistance was considered, as shown in the lower curve behavior. As stated before, these values were based in the hardness observed in each joint region.

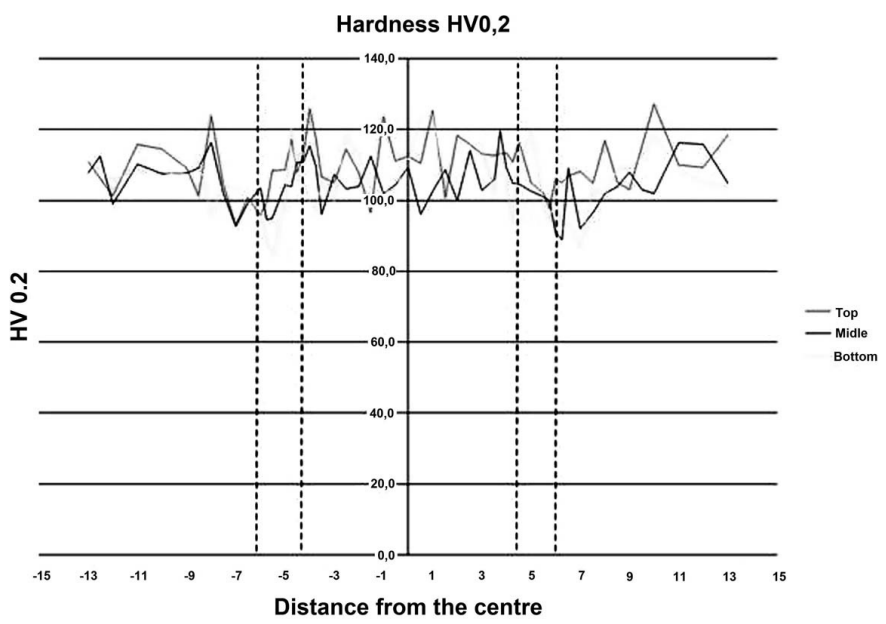

Figure 6. Typical hardness profile of AA2024-T3 FSpW joints. 


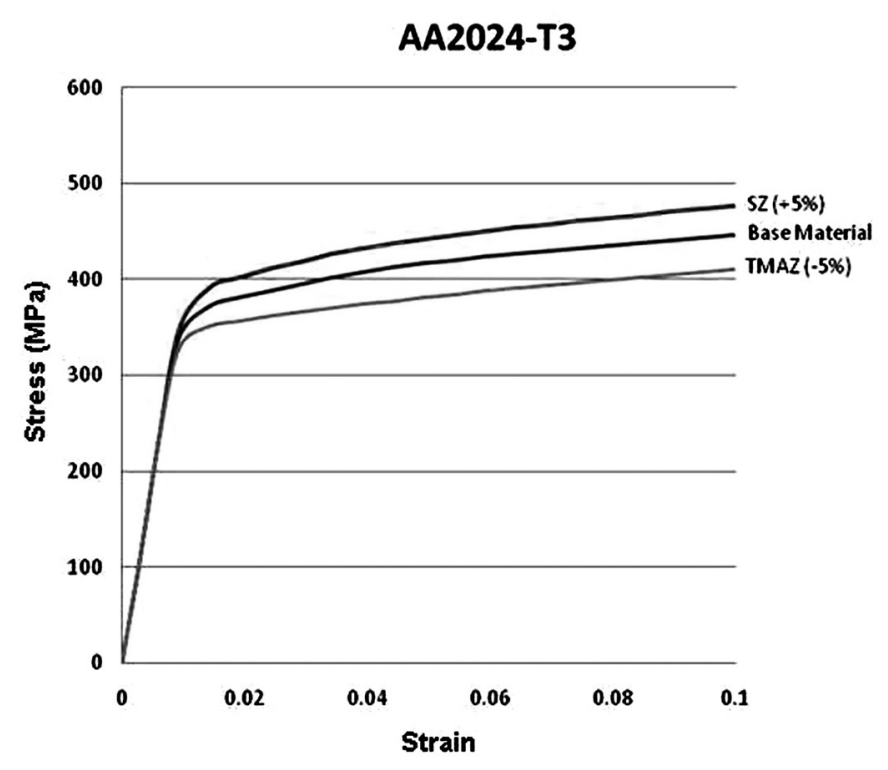

Figure 7. Engineering stress-strain curves assumed for BM, SZ and TMAZ.

\subsection{Model Characteristics}

The solid model was developed using the commercial packages SolidWorks - CAD and Abaqus - CAE [11]. Once the 3D solid parts were modeled in SolidWorks, the geometry was exported to Abaqus, where the assembly of components and specification of contact and boundary conditions, loads, and mesh characteristics were carried out.

Each one of the modeled welding joints was composed of three different parts: the Stir Zone, an Upper Plate and a Lower Plate, as seen in Figure 8.

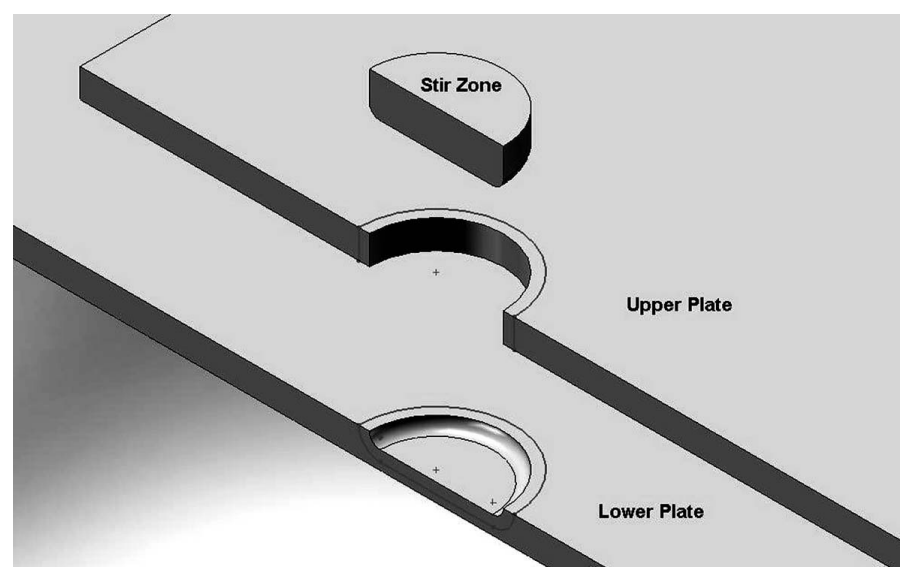

Figure 8. Welded joint composed of three different 3D parts.

The SZ, whose dimensions were shown previously in Figure 5 , and properties correspond to a mechanical resistance $5 \%$ higher than in BM.

The upper plate contains a hole where the $\mathrm{SZ}$ is accommodated and a region of constant distance around this hole that represents the TMAZ. In this region, nearby the hole, the properties correspond to the TMAZ, while in the rest of the plate the BM properties were used.

The lower plate exhibits a feature corresponding to hole left when removing SZ. As occurs in the upper plate, a region of constant width around this feature represents the TMAZ. The rest of the plate corresponds to base metal.

The assembly of the model consists of place each part in its correct relative position as can be seen in the Figure 9.

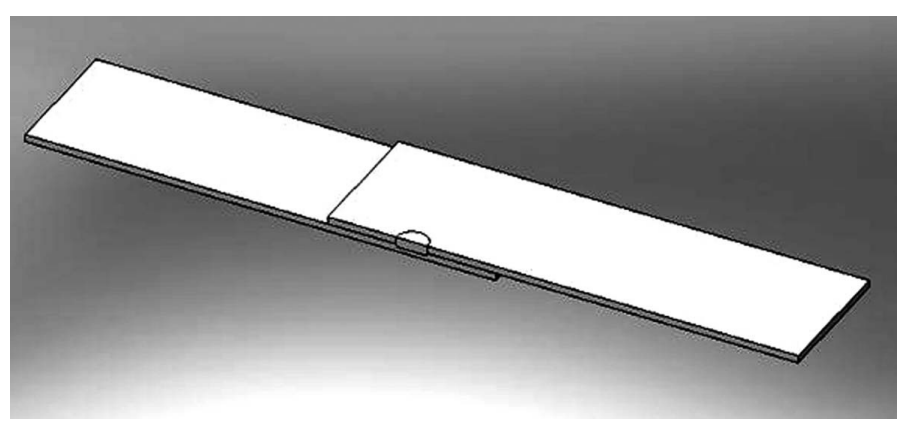

Figure 9. Aspect of the joint after assembly.

Modeling the problem as described, makes easy to assign different properties to each region, control the mesh creation and establish the contact between each one of the parts.

Once defined the weld zones dimensions and the properties of each region, the full model geometry definition was based on plates' configuration, loading and boundary conditions actually used in mechanical test specimens. The specimens currently modeled correspond to lap-shear and cross-tensile test specimens.

\section{Lap-Shear Specimen}

The DIN EN ISO 14272 standard defines conditions for lap-shear and cross-tensile tests. As shown schematically in Figure 10-a, two plates welded by FSpW in lap configuration are submitted to a uniaxial tensile load. To avoid misalignment of the plates and out of plane loading during the test, shims (represented in orange color in the figure) are placed bellow each plate.
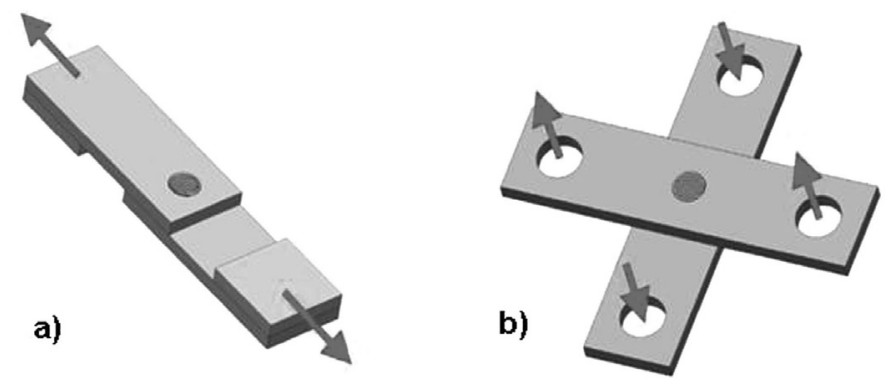

Figure 10. Schematic specimen representation from DIN EN ISO 14272: a) lap-shear and

b) cross-tensile specimen, adapted from [13].

For the lap-shear specimen, just one half of the actual specimen was modeled since there is symmetry of geometry and loads across the vertical $\mathrm{x}-\mathrm{y}$ plane as seen in Figure 11. The 
specimen size is very important to minimize the total number of finite elements necessary to represent it. Consequently the required computational resources and cost associated to the numerical simulation are reduced.

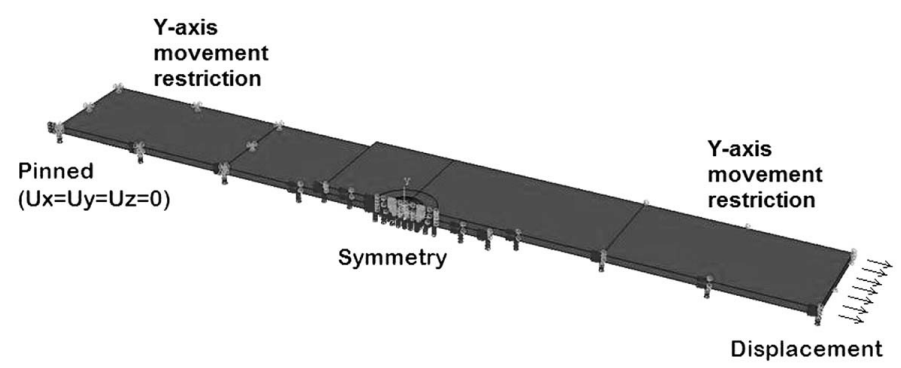

Figure 11. Lap-shear model geometry and boundary conditions.

As shown in the figure the extremity of the lower plate was pinned, what means that the displacements in the three orthogonal directions ( $\mathrm{x}, \mathrm{y}$ and $\mathrm{z}$ ) were set equal to zero. Also, the vertical movement of the external portion of both plates was not allowed, to reproduce the effect of test machine clamps. To simulate the actual load condition experimented during the test, a displacement of the external surface of upper plate was specified.

A hexahedral structured mesh was created in all the regions of each one of the three parts where eight node linear brick elements were used. The reduced integration was adopted to avoid the volumetric lock that can happen when 3D solid models are used [11]. The Figure 12-a presents the general aspect of the resulting mesh and in Figure 12-b a detail of the weld region is shown.
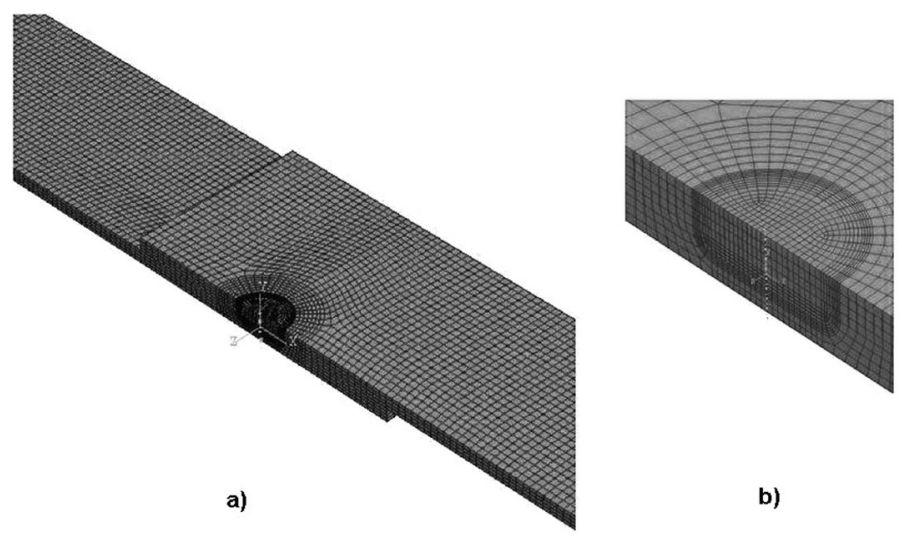

Figure 12. Aspect of the mesh created: a) general view and b) detail of the region of interest.

As the highest stresses are developed in the region of contact between the plates, the mesh density should be greater in this area. Also it is possible to notice in the detail the coherency between adjacent elements in the different parts. In this model the total number of elements was about 28000.

\section{Cross-Tensile Specimen}

The cross-tensile specimen was shown schematically in Figure 10-b. Using a specific device (not shown in the figure) two plates welded by FSpW in lap configuration are submitted to a vertical tensile load that separates them. The device allows the vertical movement of the central overlapped portion of both plates, while keeps the external portion of each part restricted.

Figure 13 presents the geometry, boundary conditions and loading used in the cross-tensile model. In this case, the entire specimen had to be modeled to avoid unrealistic results.

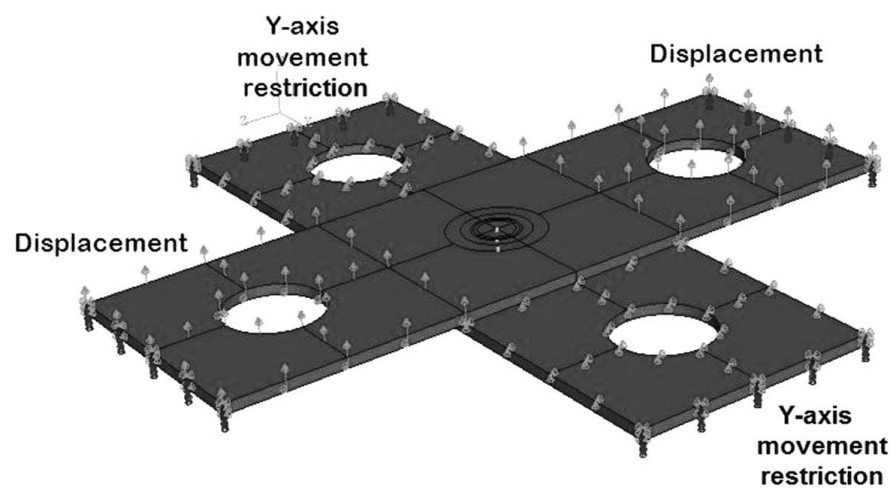

Figure 13. Cross-tensile model geometry and boundary conditions.

To reproduce the test the following boundary conditions were used in the model: the external portions of lower plate had its vertical movement constrained while a displacement was specified to the external portions of the upper plate. In this way these portions remain parallel during the simulation

The mesh in this model has the same properties that previously described for the lap shear specimen. Figure 14 shows the final aspect of the model after meshing.

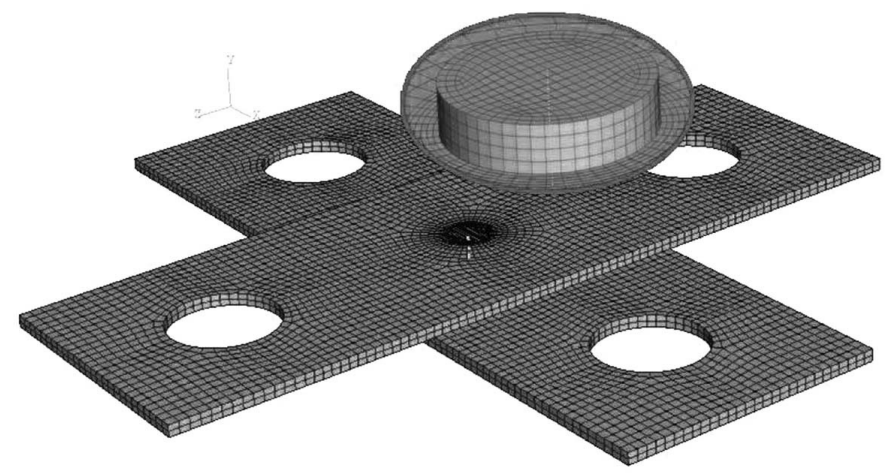

Figure 14. Aspect of the mesh created in the model containing a detail of the region of interest.

For clarity purposes, the upper sheet is not visible in the detail. As in the model previously presented, we can see a perfect connection between elements in adjacent parts.

After the specifications of the models were concluded, a series of tests to correctly setup the model was carried out. There were tested different contact conditions between the parts, load values and mesh parameters.

In Abaqus it is necessary to specify user defined analysis steps where some set of conditions are applied. In the models developed during this work, the first step was used just to 
establish the contact between the parts present in the assembly and in the second step the external load was effectively applied to the joint. It is worth noting that during the latter step the specified load condition, in this case a displacement, was applied as a ramp from zero to the final value specified.

\section{Results and Discussion}

The results obtained from simulations have shown that the increase in the stress levels occurs predominantly around the contact surface between the plates, as seen in Figure 15 to the lap-shear test simulation.

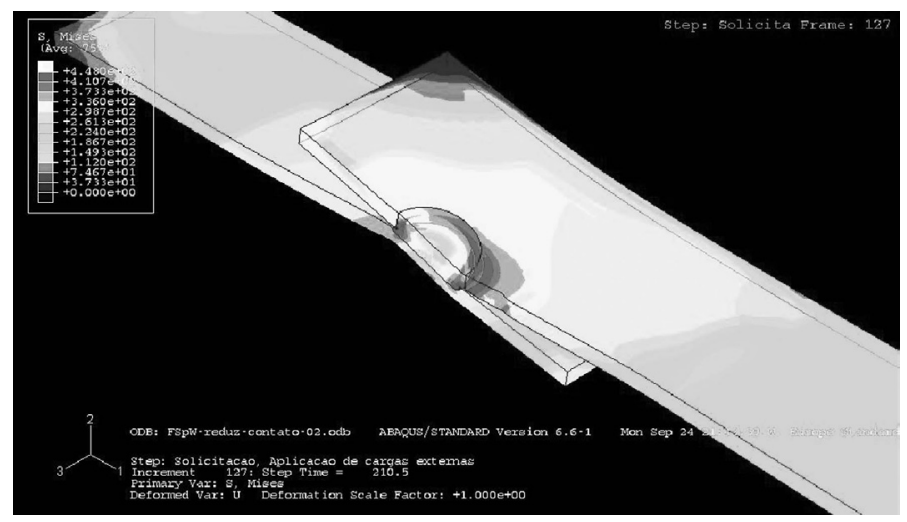

Figure 15. Simulation image of the final deformed shape of lap-shear specimen.

It is observed the stress distribution points to a progressive increase in the concentration of the higher stresses around the annular contact region between the two plates. The degree of elastic and plastic distortion was similar to that observed during and after the actual experiments.

During simulation, as the load produced by the relative displacement between the plates is increased, the region of stress concentration is formed around the contact region as seen in the Figure 16.

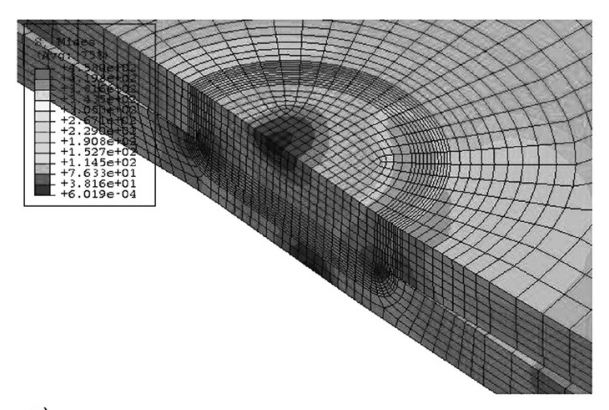

a)
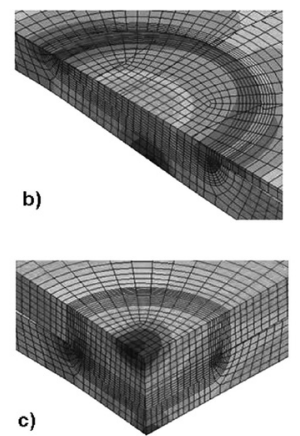

at this moment the stresses in the surroundings of this region are reasonably low.

A further increase in load from this point increases the internal stresses which reach the material ultimate tensile strength as seen in Figure 17. The specimen failure mode will depend on how the fracture develops.

From Figure 17 the region of higher stresses extends towards to the upper plate top surface, indicating a possible plug pull-out (Figure 18-a). This failure mode is associated to the combination of process parameters able to produce sound high resistance welds.

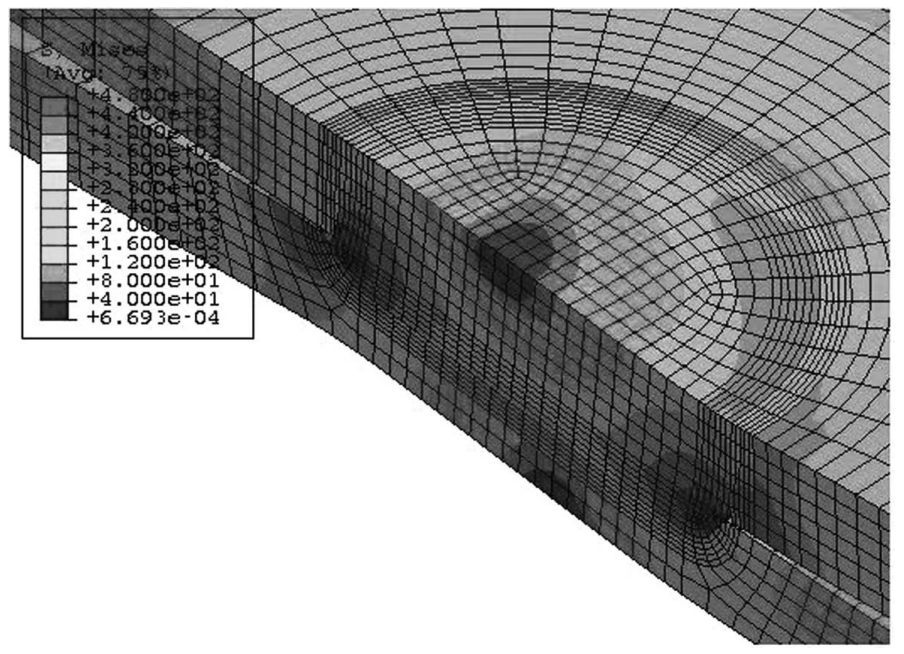

Figure 17. Stress distribution when $r$ is reached.

The through weld failure mode, shown in Figure 18-b, is associated to low load capacity.

The results of the simulations performed allowed to identify the plug pull-out failure mode. This behavior makes sense since the model exhibits no discontinuities as in the case of actual welds

It is worth to observe that the center of the stir zone has reached very low stress values, indicating that even containing a remaining hole as in the case of FSSW process, the joints can exhibit good mechanical properties.

During the experiments, the total welding time of $3.8 \mathrm{~s}$ was equally divided during shoulder plunge and retract time (1.9 $\mathrm{s}$ each). Different plunge depths, as well as shoulder plunge and retract rotational speeds were used. In these tests no dwell time was used, both pin and shoulder have been retracted as soon as the required plunge depth has been achieved. Table 2 summarizes the set of parameters used to produce the lap-shear and cross-tensile specimens and the maximum force observed in the lap-shear test [16].

Figure 16. a) Stress distribution in the contact region when the maximum stress is close to $r$,

b) horizontal cut and c) vertical cut.

Figure 16-a shows that at the boundary of the contact region, the stresses reach their highest values. A horizontal cut throughout this region (Figure 16-b) shows that an annular high stress region is formed. A vertical cut (Figure 16-c) confirms that 

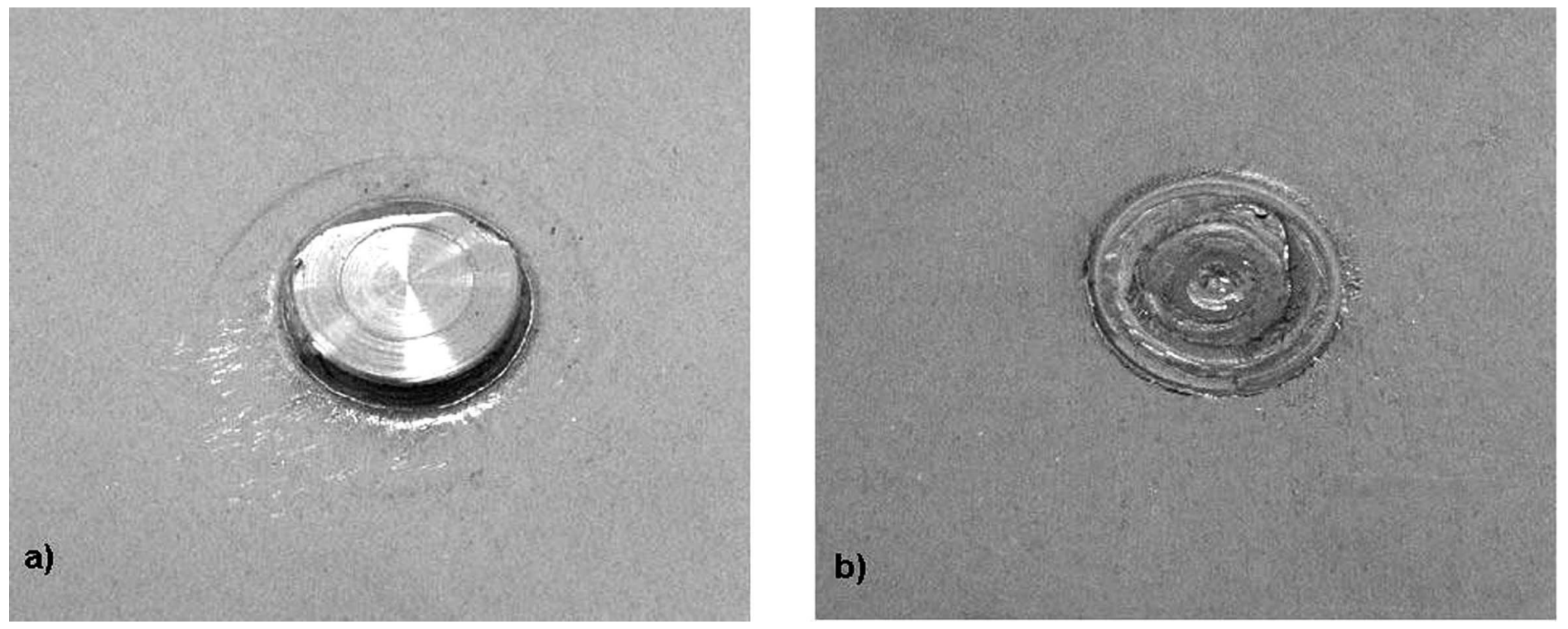

Figure 18. a) Plug pull-out and b) Through-weld final fracture aspects [12].

Table 2. Welding parameters used to produce the test specimens, adapted from [16].

\begin{tabular}{|c|c|c|c|c|}
\hline $\begin{array}{c}\text { Welding } \\
\text { condition }\end{array}$ & $\begin{array}{c}\text { Shoulder plunge } \\
\text { depth (mm) }\end{array}$ & $\begin{array}{c}\text { Shoulder plunge } \\
\text { rotational speed (rpm) }\end{array}$ & $\begin{array}{c}\text { Shoulder retract } \\
\text { rotational speed (rpm) }\end{array}$ & $\begin{array}{c}\text { Maximum Force } \\
\text { in lap-shear test } \\
(\mathrm{kN})\end{array}$ \\
\hline 1 & 0.2 & 2900 & 2700 & $7.0 \pm 0.7$ \\
\hline 2 & 0.2 & 2400 & 2200 & $8.7 \pm 0.6$ \\
\hline 3 & 0.2 & 1900 & 1700 & $6.7 \pm 0.8$ \\
\hline 4 & 0.5 & 2900 & 2700 & $8.2 \pm 1.7$ \\
\hline 5 & 0.5 & 2400 & 2200 & $8.8 \pm 0.2$ \\
\hline 6 & 0.5 & 1900 & 1700 & $9.0 \pm 1.9$ \\
\hline
\end{tabular}

The dimensions of the different joint regions (SZ, TMAZ and HAZ shown in Figure 5) were defined based in the actual values observed in a joint produced using welding condition number 6 . A comparison between the results of a lap-shear test performed in a specimen welded at this condition and the test numerical simulation is shown in Figure 19. The maximum force obtained from the simulation is very similar to the value attained during the actual test but the curve profile is different.

Since no failure criterion has been used in this work, the shape of the simulation curve after the occurrence of yielding does not represents the actual behavior of the specimen. However, the numerical results obtained are coherent with the experimental values and allow to estimate the order of magnitude of joint strength, when comparing different joint geometries.

The simulations performed in the cross-tensile model exhibit similar results. Figure 20 shows the distribution of stresses. The detail of the joint region presents a stress distribution very similar to that observed in the lap-shear simulation.

The presence of known discontinuities such as clad not homogeneously dissolved in the plates contact region can produce a change in failure mode from plug pull-out to through weld with significant decrease in joint resistance. This situation was not studied in the present work.

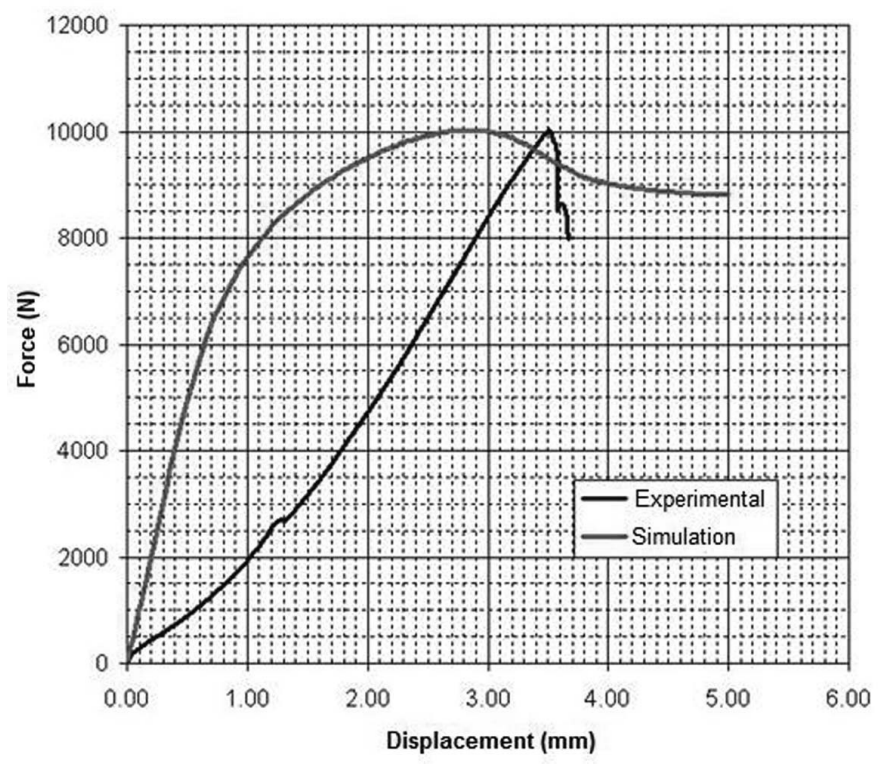

Figure 19. Comparison between experimental and numerical results of lap-shear test performed in a weld joint obtained using welding condition number 6 . 

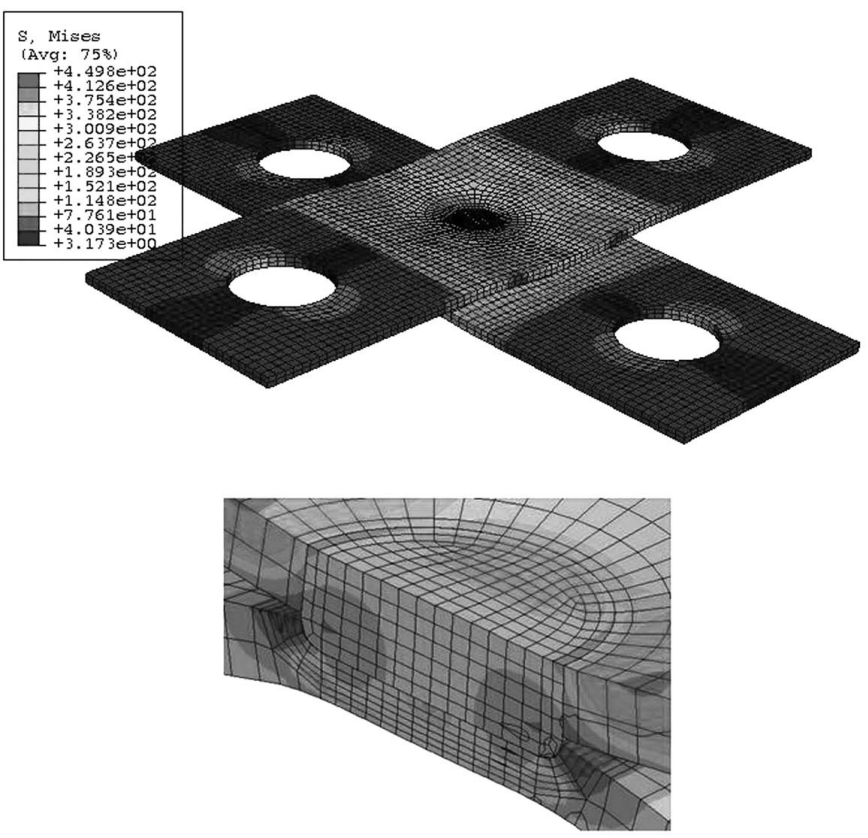

Figure 20. Stress distribution during cross-tensile test simulation. Top - general view and bottom - detail of plates contact region.

\section{Conclusions}

Numerical models corresponding to lap-shear and crosstensile test specimens were developed. The simulations have produced similar levels of stresses and distortions when compared with actual test results.

In the situations simulated, the stresses reached the ultimate tensile strength of material in an annular region around the joining area. Further increase in load extended this region towards the upper plate top surface creating a condition where a plug pull-out mode of fracture should occur.

\section{Acknowledgements}

The authors would like to thank the CAPES/DAAD for the PROBRAL program financial support and to RIFTEC $\mathrm{GmbH}$ for the production of welded specimens.

\section{References}

[1] BENDZSAK, G. J., NORTH, T. H., LI, Z., Acta Metallurgica Materialia, 1997, 45 (4), p 1735-1745.

[2] CHAO, Y. J., QI, X., Heat Transfer and Thermo-Mechanical Analysis of Friction Stir Joining of AA6061-T6 Plates. Proceedings of the First International Symposium of Friction Stir Welding, 1999, Thousand Oaks, USA.

[3] COLEGROVE, P., Proceedings of the 2nd International Conference on Friction Stir Welding, 2nd ICFSW, Sweden 2000.

[4] XU, S., DENG, X., Two and Three-Dimensional Finite Element Models for the Friction Stir Welding, Park city, Utah, USA, May 14-16, 2003.
[5] ULYSSE, P., Three-dimensional Modeling of the Friction Stir-Welding Process, International Journal of Machine Tools \& Manufacture 42 (2002) 1549-1557.

[6] ARBEGAST, W. J., Modeling friction stir joining as a metalworking process, TMS, 2003.

[7] SCHMIDT, H., HATTEL, J., WERT, J., Model. Simul. Mater. Sci. Eng. 2004, 12, 143-157

[8] MUCI-KUCHLER, K. H., ITAPU, S. K., ARBEGAST, W. J., KOCH, K. J., Visualization of Material Flow in Friction Stir Spot Welding, SAE paper: 2005-01-3323, V114-1, 2005 Transactions Journal of Aerospace.

[9] KALAGARA, S., MUCI-KÜCHLER, K. H., Numerical Simulation of a Refill Friction Stir Spot Welding Process, Friction Stir Welding and Processing IV, TMS 2007, 369-378.

[10] ITAPU, S. K., MUCI-KÜCHLER, K.H., Visualization of Material Flow in the Refill Friction Stir Spot Welding Process, SAE paper 2006-01-1206.

[11] ABAQUS/CAE User's Manual, version 6.3, Hibbit, Karlsson \& Sorensen, Inc, 2002.

[12] ROSEndo, T., SILVA, A. A. M., TIER, M. A. D., RAMOS, F. D., MAZZAFERRO, C. C. P., MAZZAFERRO, J. A. E., STROHAECKER, T. R., SANTOS, J.F., Preliminary Investigation on Friction Spot Welding of Alclad 2024 T3 Aluminium Alloy. XXXIII CONSOLDA - Congresso Nacional de Soldagem. Caxias do Sul, 27 - 30 de Agosto de 2007.

[13] TIER, M. A. D., SILVA, A. A. M., ROSENDO, T., MAZZAFERRO, J. A. E., MAZZAFERRO, C. C. P., RAMOS, F. D., STROHAECKER, T. R., SANTOS, J.F., Friction Based Spot Welding Processes - A Literature Review. To be published, 159 pg., 2007.

[14] ROSENDO, T., SILVA, A. A. M., TIER, M. A. D., RAMOS, F. D., STROHAECKER, T. R., SANTOS, J. F., Friction Spot Welding of AA2024 T3 Aluminium Alloy - A Feasibility Study. EUROMAT 2007, Nuremberg, 10th - 13th September 2007.

[15] SILVA, A. A. M., TIER, M. A. D., ROSENDO, T., RAMOS, F. D., MAZZAFERRO, C. C. P., MAZZAFERRO, J. A. E., STROHAECKER, T. R., SANTOS, J. F., Preliminary Investigations on Microstructural Features and Mechanical Performance of Friction Spot Welding of Aluminium Alloys. Proceedings of the IIW International Seminar on Friction based Spot Welding Processes. Geesthacht, 29th and 30th March 2007.

[16] SILVA, A. A. M, TIER, M. A. D., ROSENDO, T., RAMOS, F. D., MAZZAFERRO, C. C. P., MAZZAFERRO, J. A. E., STROHAECKER, T. R., SANTOS, J. F., Performance Evaluation of 2-mm Thick Alclad AA2024 T3 Aluminium Alloy Friction Spot Welding. SAE Aero Tech Congress Los Angeles, 17th - 20th September 2007.

[17] SILVA, A. A. M., SANTOS, J. F., ROSENDO, T., RAMOS, F. D., MAZZAFERRO, C. C. P., BEYER, M., TIER, M. A. D., BERGMANN, L., MAZZAFERRO, J. A. E., STROHAECKER, T. R., ISAKOVIC, J.-T., Microstructure and Properties of Friction Spot Welds in a 2-mm Thick Alclad AA2024 T3 Alloy. FABTECH International and AWS Welding Show, Chicago, IL, 11-14 November 2007. 